\title{
Connexin 43 transfection in basaloid squamous cell carcinoma cells
}

\author{
KAORI SHIMA ${ }^{1}$, TAKASHI MURAMATSU ${ }^{1}$, YOSHIHIRO ABIKO², \\ YUJI YAMAOKA $^{3}$, HODAKA SASAKI ${ }^{1}$ and MASAKI SHIMONO ${ }^{1}$ \\ ${ }^{1}$ Department of Pathology, Tokyo Dental College, 1-2-2 Masago, Mihama-ku, Chiba 261-8502; ${ }^{2}$ Division of \\ Oral Medicine and Pathology, Institute of Personalized Medical Science, Health Sciences University of Hokkaido, \\ 2-5 Ainosato, Kita-ku, Sapporo 002-8072; ${ }^{3}$ Division of Oral Functional Science, Department of Oral Functional \\ Anatomy, Hokkaido University, North 8, West 5, Sapporo 060-0808, Japan
}

Received January 30, 2006; Accepted April 13, 2006

\begin{abstract}
To investigate the relationship between the expression of connexin in basaloid squamous cell carcinomas (BSCC) and their rapid proliferation and invasive potential, we examined the effect of overexpression of connexin 43 $(\mathrm{Cx} 43)$ in a BSCC-derived cell line (BSC-OF). BSC-OF was transfected with $\mathrm{Cx} 43$ to obtain 15 clones with a stable expression of $\mathrm{Cx} 43$. In these cells, although $\mathrm{Cx} 43$ was distributed throughout the cytoplasm, it did not form connexon plaque. In almost all of the clones, cell proliferation was clearly suppressed. Furthermore, we investigated cell migration and invasion in three clones that showed a remarkable down-regulation in cell growth, and found that Cx43 transfection showed no significant effect on either. These results suggest that $\mathrm{Cx} 43$ plays a role as a tumor suppressor in the cytoplasm of Cx43-transfected BSC-OF cells. However, no definite correlation was found between Cx43 and cell migration and invasion.
\end{abstract}

\section{Introduction}

Gap junctions are an intercellular connection system, forming channels between cells and mediating the transfer of molecules smaller than 1000 daltons, ions and various second messengers. Gap junctions are formed by the docking of two connexons, each oligomer consisting of six connexin $(\mathrm{Cx})$ molecules (1-3). Cx is a transmembranous protein, forming a multi-gene family classified by their molecular weight. There are more than 12 kinds of connexin in mammalian tissue. In

Correspondence to: Dr Masaki Shimono, Department of Pathology, Tokyo Dental College, 1-2-2 Masago, Mihama-ku, Chiba 261-8502, Japan

E-mail: shimono@tdc.ac.jp

Key words: connexin 43, gap junction, transfection, basaloid squamous cell carcinoma most cells, connexons are made up of more than two types of connexin, with each pair of different Cxs forming a heteromeric connexon $(1,2)$. Cx26 and 43 are distributed variably in the keratinocytes of squamous epithelium $(3,4)$.

Disruption of connexins has been frequently reported in malignant tumor cells such as hepatocellular carcinoma (5) and breast carcinoma (6), and in carcinogenesis of the cervix (7) and endometrium (8). Saitoh et al demonstrated changes in the expression of Cx26 and 43 in hamster tongue epithelium during wound healing and carcinogenesis (9). However, few studies have investigated changes in the expression of Cx43 in oral squamous cell carcinoma (SCC) (10). Therefore, we investigated the effect of overexpression of $\mathrm{Cx} 43$ in oral carcinoma cells.

Basaloid squamous cell carcinoma (BSCC) is a relatively rare subtype of oral SCC that reveals rapid growth and aggressive local invasive potential, and its prognosis is much poorer than that of other SCCs $(11,12)$. We hypothesized that the rapid proliferation and invasive potential of BSCC would have some relationship with expression of $\mathrm{Cx} 43$, and used BSC-OF cells derived from BSCC of the floor of the mouth. BSC-OF has shown more aggressive proliferation, invasion, and motility than other oral SCC cell lines (13). In this study, we investigated whether overexpression of $\mathrm{Cx} 43$ in BSC-OF cells affected their malignant characteristics, proliferation, phagokinetics or invasive potential.

\section{Materials and methods}

Cell culture and confirmation of expression of Cx43. BSC-OF cells were grown in D-MEM/F12 (Invitrogen, Carlsbad, CA, USA) supplemented with $10 \%$ FBS, $1 \%$ penicillin-streptomycin and $0.1 \%$ gentamycin (Invitrogen) solution at $37^{\circ} \mathrm{C}$ in $5 \% \mathrm{CO}_{2}$ atmosphere. Saos-2 cells derived from osteosarcoma were cultured in D-MEM (Invitrogen) for use as a positive control. Total-RNA was extracted from the cells at confluence by AGPC method with TRIzol ${ }^{\circledR}$ (Invitrogen). To confirm expression of Cx43, conventional RT-PCR was performed. The sequence of the forward primer was 5'-gaattctggttatcatgt cggggaa-3', and the reverse primer was 5'-taccatgcgaccagtggt gcgct-3' (14). 
Vector construction and transfection. cDNA from the human Cx43 coding region was amplified by PCR with the following primers: forward 5'-cacaattgagtggaatcttgatg-3'; reverse 5'-caa catgggtgactggagc-3'. PCR product was purified and inserted into the mammalian expression vector (pTARGET, Promega, Madison, WI, USA). Expression vector was transfected into BSC-OF cells by the lipofection method using Lipofectamin ${ }^{\mathrm{TM}}$ Reagent (Invitrogen). Subclones were selected by ampicillin and $400 \mu \mathrm{g} / \mathrm{ml}$ antibiotic G418 sulfate (Calbiochem, San Diego, CA, USA). Cells of the subclones were diluted and seeded to obtain further clones.

Western blotting. Total cell lysate was obtained from the BSC-OF and 15 clones with RIPA buffer ( $\mathrm{pH}$ 7.2) which included the protease inhibitors, aprotinin, leupeptin, PMSF, $\mathrm{Na}_{3} \mathrm{VO}_{4}$ and MG132. SDS-PAGE (12\%) was performed with $50 \mu \mathrm{g}$ protein of each sample, and transferred to PVDF membrane (Bio-Rad, Hercules, CA, USA) at $4^{\circ} \mathrm{C}$ for $1 \mathrm{~h}$. After blocking the non-specific reaction, anti-Cx43 polyclonal antibody (1:1000, Zymed, South San Francisco, CA, USA) was applied and incubated at $4^{\circ} \mathrm{C}$ overnight. After washing in TBS with $0.1 \%$ Triton- $\mathrm{X}$, horseradish peroxidase conjugated antirabbit IgG (Amersham, Buckinghamshire, UK) was applied for $1 \mathrm{~h}$. To detect expression of $\mathrm{Cx} 43, \mathrm{ECL}^{\mathrm{TM}}$ Western Blotting Detection Reagents (Amersham Bioscience) was used.

Immunofluorescence analysis. Cells were seeded on cover slips at the bottom of the culture dishes until they became subconfluent and then fixed with acetone and methanol for $20 \mathrm{~min}$. To block non-specific reaction, goat normal serum was applied for $30 \mathrm{~min}$, and then anti-Cx43 monoclonal antibody (1:300, Chemicon, Temecula, CA, USA) was applied at room temperature for $1 \mathrm{~h}$. After washing, anti-mouse IgG, Alexa fluor ${ }^{\circledR} 488$ (1:500, Molecular Probes, Eugene, OR, USA), and To-PRO ${ }^{\circledR}-3$ iodide (1:500, Molecular Probes) for nuclear staining were applied at room temperature for $1 \mathrm{~h}$. Observation was performed by fluorescence microscopy with the Axiophot2. (Carl Zeiss, München-Hallbergmoos, Germany).

Cell proliferation assay (screening). A $1 \times 10^{4}$ aliquot of cells of BSC-OF and all clones were seeded onto the cell culture dishes. After one to seven days, cells were detrypsinized and the total number counted in triplicate using an erithrocytometer.

Migration assay. Phagokinetic assay was performed by modified Albrecht-Buehler's method (15). Three clones (A4, $9,13)$ that showed remarkable down-regulation of cell proliferation were selected. A $1 \times 10^{4}$ aliquot of cells of BSC-OF and the three clones were then plated onto the cover slips coated with colloidal gold salts $\left(145 \mathrm{mM} \mathrm{AuCl}{ }_{4} \mathrm{H}\right)$, and cultured in DMEM/F12 containing 1\% FBS for $24 \mathrm{~h}$ respectively. Then, more than 30 phagokinetic tracks per cell were measured by computer-assisted image.

Invasion assay. A $1 \times 10^{5}$ aliquot of cells of BSC-OF and the three clones $(\mathrm{A} 4,9,13)$ were plated onto a 6-well BioCoat ${ }^{\mathrm{TM}}$ Matrigel $^{\mathrm{TM}}$ Invasion Chamber (BD Biosciences, San Jose, CA, USA) and cultured for $24 \mathrm{~h}$, respectively. Cells digested

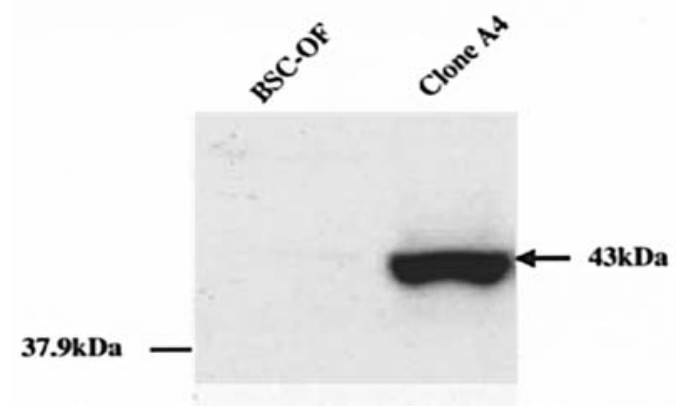

Figure 1. Expression of transfected Cx43 confirmed by $12 \%$ SDS-PAGE and Western blotting. Fifteen clones expressing transfected Cx43 were obtained.

the matrigel, enabling them to pass through the micro-pores in the gel, after which, they were fixed and stained. The numbers of invasion cells were counted per $1 \mathrm{~mm}^{2}$ at the central area of the matrigel.

Statistical analysis. Phagokinetic tracks and invasion indexes were analyzed by one-way factorial ANOVA and multiple comparison tests.

\section{Results}

Confirmation of transfection. Weak expression of mRNA of Cx43 was identified in BSC-OF parent cells by comparison with Saos-2. A slight increase in $\mathrm{Cx} 43$ expression was observed in all clones (A1-15) by RT-PCR, and Western blotting (Fig. 1). However, no quantitative differences in expression of $\mathrm{Cx} 43$ were found among the clones.

Localization of Cx43. Immunofluoresence analysis revealed a more strongly defined immunopositive signal for $\mathrm{Cx} 43$ in all clones than in the BSC-OF parent cells. However, although Cx43 was distributed evenly throughout the cytoplasm, no signal was observed in the intercellular areas of any of the clones. In the positive control, Saos-2, Cx43 displayed punctuated signals in the intercellular area (Fig. 2).

Growth characteristics. In most of the Cx43-transfected clones, cell proliferation showed greater down-regulation than in the BSC-OF parent and mock cells. Remarkable down-regulation of cell proliferation was distinct in three clones, A4, 9 and 13 (Fig. 3).

Migration assay. The averaged phagokinetic tracks revealed a slight increase in A9 and a decrease in A4 compared to in BSC-OF (Table I). However, there were no significant differences between BSC-OF and the other three clones.

Invasion assay. The number of cells that invaded the matrigel is indicated by the invasion index (Table II). The cell invasion index showed an increase in clone A9 and a decrease in clone A13 compared to in BSC-OF, although there were no significant differences. A9 and A13, however, showed a significant difference in invaded cell number. 

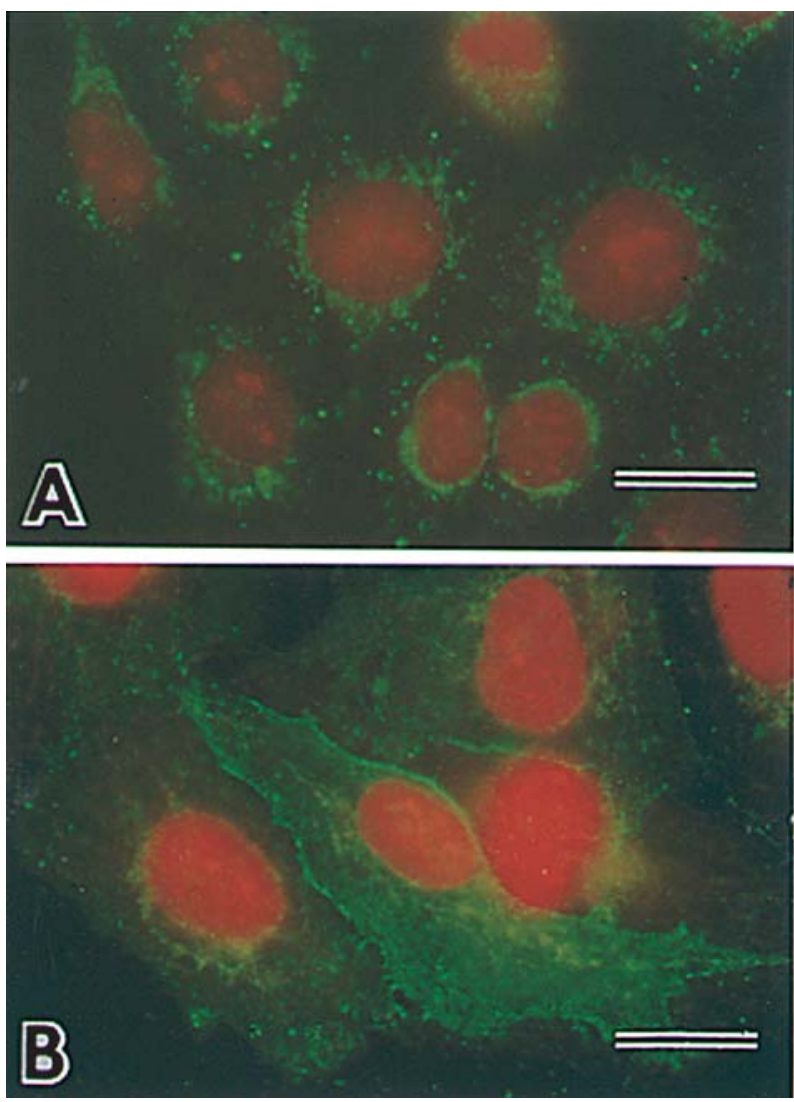

Figure 2. (A), Dot-shaped Cx43 distributed not at intercellular region but in cytoplasm of clone A4. (Bar=20 $\mu \mathrm{m}$ ). (B), In Saos-2 (positive control) endogenous $\mathrm{Cx} 43$ distinct in intercellular region. (Bar=20 $\mu \mathrm{m})$.

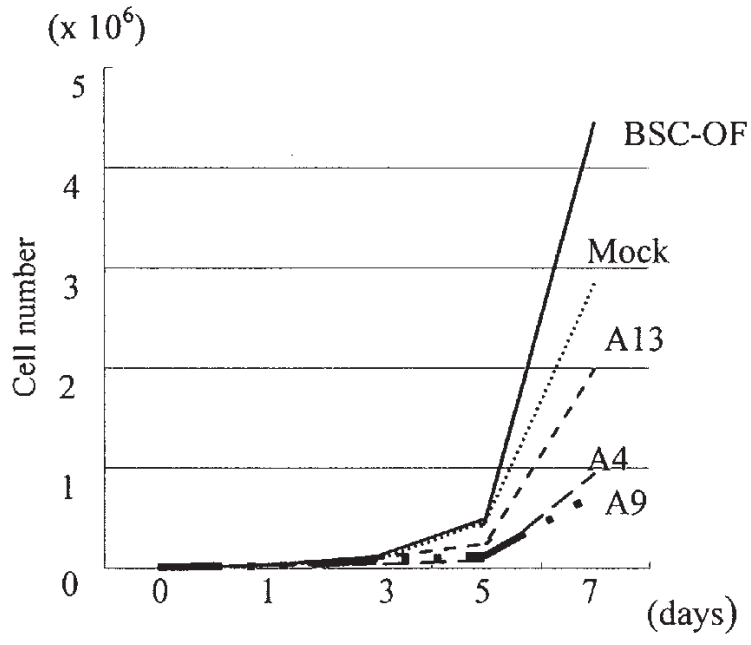

Figure 3. Effect of transfected Cx43 on proliferation of BSC-OF. Proliferation curve shows cell growth of three clones markedly suppressed.

\section{Discussion}

In squamous epithelium, $\mathrm{Cx} 43$ is mainly expressed in the basal layer, forming gap junctions as an intercellular communication system (4). Generally, Cx decreases in malignant tumors in which intercellular communication may be lost (5-8). As a
Table I. Migration index.

\begin{tabular}{lc}
\hline Cell & Phagokinetic track $\left(\mathrm{x} 10^{3} \mathrm{~mm}^{2}\right)$ \\
\hline BSC-OF & $2.45 \pm 0.87$ \\
Clone A4 & $2.40 \pm 0.54$ \\
Clone A9 & $2.94 \pm 1.17$ \\
Clone A13 & $2.42 \pm 0.80$ \\
\hline
\end{tabular}

Table II. Cell invasion index.

\begin{tabular}{lc}
\hline Cell & Cell no. $\left(/ \mathrm{mm}^{2}\right)$ \\
\hline BSC-OF & $1.285 \pm 0.747$ \\
Clone A4 & $1.187 \pm 0.772$ \\
Clone A9 & $2.887 \pm 0.263 \quad \square *$ \\
Clone A13 & $0.434 \pm 0.139 \quad \square$ \\
\hline
\end{tabular}

* $\mathrm{p}<0.05$.

result, the nest of tumors expands and shows invasive growth into neighboring or distant tissues.

We investigated the effect of $\mathrm{Cx} 43$ transfection in BSC-OF oral carcinoma cells. All of the monoclonal Cx43 transfectants revealed increased expression of $\mathrm{Cx} 43$. However, although Cx43 was distributed throughout the cytoplasm, it did not form gap junctions in any of the clones. This result was supported by the scrape loading method (data not shown).

All the clones we obtained showed suppressed cell proliferation in comparison to the parent and mock cells. It has been suggested that transfection-induced abundance of $\mathrm{Cx} 43$ suppresses tumor proliferation, particularly in clone A9. Zhang et al have demonstrated that, in osteosarcoma cell line U2OS, the C-terminal of $\mathrm{Cx} 43$ binds the S-phase kinase-associated protein (Skp2), which inhibits ubiquitination of p27, the cell cycle regulator in the G1-S phase (16). Cx43 has been shown to cause an increase in $\mathrm{p} 27$ without forming gap junctions, leading to a reduction in the cell cycle $(17,18)$. In oral SCC, it is unclear whether $\mathrm{Cx} 43$ inhibits p27 degradation, and we found no clear evidence of an interaction between Cx43 and Skp-2. However, our findings do suggest that abundant Cx43 not forming gap junctions in the cytoplasm indicates involvement in cell cycle regulation.

Generally, oral carcinoma cells frequently destroy the basement membrane, infiltrating deeply and metastasizing to the lymph nodes of the neck region (19). Loss of intercellular communication causes each individual cell to migrate. Graeber et al noted that, in HeLa cells, Cx transfection, especially with $\mathrm{Cx} 43$, induced invasive properties (20). In their investigation, Cx43-transfected HeLa cells formed gap junctions and became involved in intercellular communication. In our results, however, transfection with $\mathrm{Cx} 43$ showed no effect on cell motility or invasion, although the transfected $\mathrm{Cx} 43$ was 
distributed throughout the cytoplasm, it did not form gap junctions, and, therefore, did not influence intercellular communication. For cell migration to take place, a change in cell skeletal protein is necessary. Cx43 in the cytoplasm may not interact with actin, tublin, or various filaments (21).

Our results suggest that one of the important factors is whether transfected $\mathrm{Cx} 43$ forms gap junctions or not. Zhu et al also investigated the effect of Cx43 transfection on C6 glioma cells, obtaining clones that showed various amounts of $\mathrm{Cx} 43$ displayed both at areas of intercellular contact and in the cytoplasm (22). The precise mechanism behind the occasional high expression of gap junctions in the clones remains to be determined. Momiyama et al observed the same phenomenon, finding Cx26 transfection in breast cancer cells produced clones both with and without gap junctions (23). In forming gap junctions in the process of intracellular transportation, the assembly, detachment, and degradation of Cxs is correlated with their phosphorylation (2,21). Cx43 phosphorylation is highly regulated during the cell cycle (24). The rise of intracellular cyclic AMP also promotes the assembly of connexons, which results in an increase in gap junctions (21). Depending on the clone, there may be differences in the level of cyclic AMP or phosphorylation. We surmise that phosphorylation of $\mathrm{Cx} 43$ may occur only rarely in $\mathrm{BSC}-\mathrm{OF}$, making it difficult for $\mathrm{Cx}$ to present itself for the construction of gap junctions.

In conclusion, transfected $\mathrm{Cx} 43$ in BSC-OF was found in the cytoplasm, clearly inducing tumor suppression. In terms of cell invasion and motility, there were significant differences between the parent cells and the Cx43 transfectant. Proliferation in clone A9 was suppressed remarkably, although both cell migration and motility were promoted.

\section{Acknowledgements}

The authors wish to express their appreciation to Mr. Katsumi Tadokoro and Dr Masahiro Ryu for their contribution to this manuscript. This study was supported in part by the Japanese Ministry of Education, Culture, Sports, Science and Technology, Grant-in-aid No. 14657489 and 14771012.

\section{References}

1. Kumar NM and Gilula NB: The gap junction communication channel. Cell 84: 381-388, 1996.

2. Goodenough DA, Goliger JA and Paul DL: Connexins, connexons and intercellular communication. Annu Rev Biochem 65: 475-502, 1996.

3. Dermietzel R, Hwang TK and Spray DS: The gap junction family: structure, function and chemistry. Anat Embryol (Berl) 182: 517-528, 1990.

4. Kamibayashi Y, Oyamada M, Oyamada Y and Mori M: Expression of gap junction proteins connexin 26 and 43 is modulated during differentiation of keratinocytes in newborn mouse epidermis. J Invest Dermatol 101: 773-778, 1993.

5. Ma XD, Sui YF and Wang WL: Expression of gap junction genes connexin 32, connexin 43 and their proteins in hepatocellular carcinoma and normal liver tissues. World J Gastroenterol 6: 66-69, 2000.
6. Saunders MM, Seraj MJ, Li Z, et al: Breast cancer metastatic potential correlates with a breakdown in homospecific and heterospecific gap junctional intercellular communication. Cancer Res 61: 1765-1767, 2001.

7. King TJ, Fukushima LH, Hieber AD, Shimabukuro KA, Sakr WA and Bertram JS: Reduced levels of connexin43 in cervical dysplasia: inducible expression in a cervical carcinoma cell line decreases neoplastic potential with implications for tumor progression. Carcinogenesis 21: 1097-1109, 2000.

8. Saito T, Nishimura M, Kudo R and Yamasaki H: Suppressed gap junctional intercellular communication in carcinogenesis of endometrium. Int J Cancer 93: 317-323, 2001.

9. Saitoh M, Oyamada M, Oyamada Y, Kaku T and Mori M: Changes in the expression of gap junction proteins (connexins) in hamster tongue epithelium during wound healing and carcinogenesis. Carcinogenesis 18: 1319-1328, 1997.

10. Livny O, Kaplan I, Reifen R, Polak-Charcon S, Madar Z and Schwartz B: Oral cancer cells differ from normal oral epithelial cells in tissue like organization and in response to lycopene treatment: an organotypic cell culture study. Nutr Cancer 47: 195-209, 2003.

11. Coppola D, Catalano E, Tang CK, Elfenbein IB, Harwick R and Mohr R: Basaloid squamous cell carcinoma of floor of mouth. Cancer 72: 2299-2305, 1993.

12. Coletta RD, Cotrim P, Vargas PA, et al: Basaloid squamous carcinoma of the oral cavity: report of 2 cases and study of AgNOR, PCNA, p53 and MMP expression. Oral Surg Oral Med Oral Pathol Oral Radiol Endod 91: 563-569, 2001.

13. Abiko Y, Okumura K, Ohuchi T, Konishi T, Kanazawa M and Kaku T: Basaloid-squamous cell carcinoma of the floor of the mouth: characterization of a cell line. J Oral Pathol Med 26: 367-370, 1997.

14. Oviedo-Orta E, Hoy T and Evans WH: Intercellular communication in the immune system: differential expression of connexin 40 and 43 , and perturbation of gap junction channel functions in peripheral blood and tonsil human lymphocyte subpopulations. Immunology 99: 578-590, 2000.

15. Albrecht-Buehler G: The phagokinetic tracks of 3T3 cells. Cell 11: 395-404, 1977.

16. Zhang YW, Nakayama $\mathrm{K}$ and Morita I: A novel route for connexin 43 to inhibit cell proliferation: negative regulation of S-phase kinase-associated protein (Skp 2). Cancer Res 63: 1623-1630, 2003

17. Moorby C and Patel M: Dual functions for connexins: Cx43 regulates growth independently of gap junction formation. Exp Cell Res 271: 238-248, 2001.

18. Zhang YW, Kaneda M and Morita I: The gap junctionindependent tumor-suppressing effect of connexin 43. J Biol Chem 278: 44852-44856, 2003.

19. Nagpal JK and Das BR: Oral cancer: reviewing the present understanding of its molecular mechanism and exploring the future directions for its effective management. Oral Oncol 39: 213-221, 2003.

20. Graeber SH and Hulser DF: Connexin transfection induces invasive properties in HeLa cells. Exp Cell Res 243: 142-149, 1998.

21. Lampe PD and Lau AF: Regulation of gap junctions by phosphorylation of connexins. Arch Biochem Biophys 384: 205-215, 2000.

22. Zhu D, Caveney S, Kidder GM and Naus CC: Transfection of C6 glioma cells with connexin 43 cDNA: analysis of expression, intercellular coupling and cell proliferation. Proc Natl Acad Sci USA 88: 1883-1887, 1991

23. Momiyama M, Omori Y, Ishizaki Y, et al: Connexin26mediated gap junctional communication reverses the malignant phenotype of MCF-7 breast cancer cells. Cancer Sci 94: 501-507, 2003.

24. Solan JL and Lampe PD: Connexin phosphorylation as a regulatory event linked to gap junction channel assembly. Biochim Biophys Acta 1711: 154-163, 2005. 